Bill, the only difference being, that the annual medical directory of each kingdom would contain a distinct alphabetical list of each class of practitioners, instead of a mixed alphabetical list of all persons qualified to practise. The distinction between the surgeon, and the apothecary or general practitioner, would be, that the former does not practise pharmacy.

" "The form of certificate in schedule B. should be made to correspond with the description of the qualification in the register. With the above alterations, we think no reasonable objections could be urged against the Bill, which appears to be simple, practicable, and likely to effect the object contemplated." "

The suggestion, as we have before remarked, derives its claim to notice from its having been adopted by the Editor of the Iledical Press, who seems to have been led by his views on another evil connected with the present state of the profession, to give the weight of his authority to a proposal which, probably, under other circumstances, he would have disapproved of.

None can be more fully impressed than we are with the unmitigated evils arising from the system of "keeping open shop," the combining of a retail trade with a scientific profession, or the attempt at estimating the value of the services of any medical practitioner by a sum made up of paltry items of shillings and pence, charged on the drugs supplied; but this is a distinct question, and ought not to be suffered to interfere with the settlement of one of the leading measures for a reform of our institutions, on broad and equitable principles.

The true intent of the registration, that which gives to it its main advantage to the profession and utility to the public, is the clear distinction which it at once establishes between the qualified practitioner and the ignorant pretender. It is the common ground on which qualified medical practitioners of every grade or denomination can meet; if carried out in its original simplicity, it will unite them, and them only, into one general body, and for public purposes mark them as such, leaving the separate registration of all distinctions of grade, designation, \&c., to the several corporate bodies by which these distinctions are conferred.

If we are to have class distinctions introduced into the register, there is no drawing the line where this hair-splitting would end. The licentiates of one corporation may consider themselves entitled to register in one grade, while those of another corporation may not be disposed to recognise the former as equals, till at length we may have as many divisions introduced into the register as there are licensing bodies.

Neither is the practice of the different grades so defined as to render the adoption of this distinction a satisfactory ground of classification. Where, for instance, are professed accoucheurs to be placed. Some of these - the rejected from corporate honours and privileges-are university graduates, and denominated physicians; others are members of the College of Surgeons; but where are they to be placed in the registration list, if divided, as has been suggested. The fellows of the College of Physicians will scarcely see them registered as pure physicians - the council of the College of Surgeons will repudiate them from the list of pure surgeons; and, certainly, very many of them neither dispense nor supply medicine, nor have licence from the Apothecaries' Company to do so, and can have little claim, therefore, to register as general practitioners.

Other objections to this class-registration present themselves, but we are compelled to postpone the notice of them till another opportunity. The members of the Provincial Medical Association, however, will bear in mind, that the support afforded to the Registration Bill at the late Anniversary was unceimous, and that the only difference of opinion then manifested, arose out of an ambiguity, or supposed ambiguity, in the legal phraseology of one of its clauses.

ETHICS OF MEDICINE.

COMPLAINT MADE BY MR. GEORGE WIGAN, SURGEON, OF SOMERSETSTREET, AGAINST DR. GREGORY, OF WEYMOUTH-STREET.

$$
\text { To the Editor of THE LANCET. }
$$

Sir,-That you have done the medical profession much service, few, if any, will deny; but that much remains to be done is equally evident, and, $I$ fear, will ever remain so, until its members will assist you more especially in supporting their own dignity by due observance of a gentlemanly and courteous bearing towards each other. Whilst one member is ever ready to war against another, and lay prostrate, by inference or assertion, the professional character of his neighbour, that he may raise his own reputation on its ruin, the world must ever regard us with distrust, if not contempt. That this too often occurs the following case will illustrate:T have attended professionally Mrs. F- of James-street, Oxford-street, who was suffering from an attack of acute rheumatism. All severe symptoms had subsided; no pain, no fever; when, in consequence of reluctance to speak or be spoken to, the husband, from undue apprehension, and the importunities of friends, was induced, on the spur of the moment, to call in Dr. Gregory, of Weymouth-street, who came, was told I was in attendance, and although $I$ reside in an adjoining street, he did not desire to see me, but proceeded at once to question the patient- to object to what I had advised - to subvert my opinions - to declare imminent danger, even in twenty-four hours-called the disease a twenty-five day fever! and appealed to the husband's common sense, if it was likely she could survive, not half the time having elapsed. Thus, having conjured up a great enemy to subdue, a "mountain in labour," he proceeded to prescribe, and found it necessary to treat only the "ridiculus mus." His prescription, which I append, was this:-" Mercury with chalk, nine grains; (true) James's powder, eight grains; extract of henbane, eight grains: mix, and divide into six pills, one to be taken every six hours."- "Bicarbonate of potash, four scruples; srrup of orange-peel, six drachms; tincture of orange-peel, thirty minims; water, five ounces; orange-flower water, two ounces: to make a mixture, of which two table-spoonfuls are to be taken, with a dessert-spoonful of lemon-juice, every six hours." The patient followed my treatment, and, I am happy to say, recovered without a single bad symptom, before the expiration of the "twenty-five days."

I would apologize to you, Mr. Editor, in requesting your insertion of this letter, but that I am convinced of your zeal in our cause. All the efforts you have made, and are yet making, to elevate our position, will avail nothing, whilst among ourselves so much is done to prejudice it.-I am, Sir yours obediently,

Somerset-street, Portman-square, Sept. 1846.

N.B.-T called on Dr. Gregory, with a professional friend, in the evening, for an explanation, when he admitted that he never sees the practitioner in attendance unless desired by the patient to do so.

** This is a case for the investigation and decision of a court medical. The constitution of such a court was described in The Lances of Sept. 12th, p. 334. The reference of such cases to qualified members of the profession, before whom, accusers and accused, and their witnesses, would have a fair opportunity of being heard, would, we believe, be productive of the best results. The decisions of courts medical would, in a short time, operate powerfully throughout the profession. The ethics of medicine have been too long neglected.

\section{SUCCESSFUL TREATMENT OF CHOLERA IN INDIA.}

To the Editor of The Lancert.

SiR,--Having learned from the public prints that that direful plague, the Asiatic cholera, is again progressing towards Europe, which I trust a merciful Providence will avert, I cannot allow the present opportumity to slip without recording in your valuable journal the method I have found the best in my hands, for a series of years, of treating that terrible disease. Should success in combating" so formidable an affliction be the result of this communication, and the science of medicine be thereby in any degree advanced, I shall rest pleased that I have fulfilled my duty.

I need scarcely tell you, Sir, that I have been wont, for a long period, to sip knowledge from your inestimable periodical, and $I$ have therefore taken the liberty of addressing you, which I trust you will pardon, especially when I state that I hold the happiness and prosperity of my fatherland indelibly at heart. If, by the publicity of the following, those objects shall at all be realized, I shall be glad to have communicated it.

\section{TREATMENT OF CHOLERA.}

On first visiting the patient, I give, calomel, ten grains; rhubarb, ten grains; compound powder of aloes, ten grains; mixed and formed into a bolus. This $I$ follow up with ten or fifteen minims of liquor ammonia, mixed in a little cold water, and $I$ repeat this dose in half an hour, if rejected; otherwise, I give a second, and even a third dose. To quell the stomach's 